\title{
TENDÕES FLEXORES DA MÃO, UMA REVISÃO DE LITERATURA
}

\section{ARTIGO DE REVISÃO}

ALCARAS, Atila Lotufo ${ }^{1}$

ALCARAS, Atila Lotufo. Tendões flexores da mão, uma revisão de literatura. Revista Científica Multidisciplinar Núcleo do Conhecimento. Ano 06, Ed. 03, Vol. 04, pp. 05-16. Março de 2021. ISSN: 2448-0959, Link de acesso: https://www.nucleodoconhecimento.com.br/saude/tendoes-flexores, DOI: 10.32749/nucleodoconhecimento.com.br/saude/tendoes-flexores

\section{RESUMO}

O presente artigo objetiva abordar o estudo da anatomia dos tendões flexores dos dedos da mão, e suas patologias mais comuns, com o propósito de auxiliar no correto diagnóstico e tratamento das tendinopatias. Ao longo desta pesquisa explicamos a anatomia do tendão flexor e abordamos os casos mais comuns de tendinopatia, como tendinose e tenossinovite e, ainda, os seus possíveis tratamentos. Dito isso, trata-se de uma revisão literária realizada através de artigos acadêmicos, livros e outras publicações acadêmicas relacionadas ao assunto, que nos permitiu um maior conhecimento sobre as estruturas do tendão flexor da mão e dos dedos, de modo a facilitar a compreensão e a absorção das informações importantes sobre as suas características e patologias, bem como sobre os seus tratamentos adequados. Assim, em suma, descobrimos aqui a ponta de um iceberg, onde verificou-se a necessidade de uma busca contínua sobre os conhecimentos relacionados a este tema.

Palavras-chave: Tendinopatia, tenossinovite, termoterapia, terapia manual.

\footnotetext{
${ }^{1}$ Tecnólogo Em Gerenciamento De Redes De Computadores, Pós-Graduado Em Segurança De Redes De Computadores, Pós-Graduado Em Fisioterapia Traumato-Ortopédica, Formando Em Bacharel Em Fisioterapia. Centro Universitário Aparício Carvalho - FIMCA.
}

RC: 77841

Disponível em: https://www.nucleodoconhecimento.com.br/saude/tendoes-flexores 


\section{INTRODUÇÃO}

Esta pesquisa delimitou-se em colher informações sobre o estudo da anatomia dos tendões flexores dos dedos da mão, auxiliando na avaliação do paciente tendo como referência a anatomia dos tendões flexores dos dedos da mão e da patologia "tenossinovite dos tendões flexores da mão".

Frente às consequências de patologias, em especial a tenossinovite, que afastam os trabalhadores de seus postos de trabalho, e como fator evidente para uma saúde de qualidade dos trabalhadores, evitando o afastamento de suas atividades laborais, leva-nos a questionar como uma correta e fidedigna avaliação ortopédica, se torna indispensável para se ter a garantia de um correto diagnóstico.

Diagnostico que nos levará a escolha do tratamento adequado, assim o estudo da anatomia se faz necessário para escolha certa do tratamento, seja preventivo ou reabilitativo.

Como propor o tratamento certo para as patologias dos tendões flexores da mão? Este trabalho demonstra a importância em se conhecer a anatomia dos tendões flexores dos dedos da mão, para escolha de um tratamento adequado para tendinopatias.

Esta pesquisa se justifica devido à necessidade de se avaliar corretamente o paciente para definir o tratamento em casos de tendinopatias e em especial a tenossinovite, patologia que é considerada uma LER/DORT, ou seja, "lesão por esforço repetitivo/distúrbios osteomusculares relacionados ao trabalho", levando inclusive ao afastamento dos postos de trabalho e ainda em casos mais graves a aposentadoria precoce.

A Tenossinovite Estenosante dos flexores trata-se de uma doença relativamente frequente, afetando cerca de 1 a 3/1000 nascimentos (Botelheiro, 2018).

RC: 77841

Disponível em: https://www.nucleodoconhecimento.com.br/saude/tendoes-flexores 


\section{OBJETIVO GERAL}

Compreender a anatomia dos flexores da mão, para estabelecer o tratamento, nos casos de tendinopatias dos tendões flexores dos dedos da mão.

\subsection{OBJETIVOS ESPECÍFICOS}

- Investigar sobre o processo de tendinopatia;

- conhecer as estruturas dos tendões flexores dos dedos da mão;

- Relatar a tenossinovite dos flexores dos dedos da mão;

- Identificar as técnicas fisioterapêuticas no tratamento das tendinopatias dos flexores dos dedos da mão.

\section{METODOLOGIA}

Adotamos a metodologia de revisão bibliográfica, valendo-nos de publicações acadêmicas, artigos, e livros, assim orienta Gil (2008) é desenvolvida a partir de material já elaborado, constituído de livros e artigos científicos. Ainda de acordo com as definições de Miguel (2012) o escopo da presente pesquisa é temático, por ser centrada em um foco específico.

Assim elaboramos uma revisão bibliográfica básica, com claro objetivo de atualização e ampliação de conhecimentos fundamentais, para a escolha do tratamento para as tendinopatias. Revisamos livros e artigos de: Morfologia; Tratado de ultrassonografia; Anatomia; Propedêutica; Semiologia. Realizamos consultas ao Google acadêmico e a Scielo (Scientific Eletronic Library OnLine) selecionando as publicações que contenham uma linguagem mais clara e objetiva ao nosso trabalho, e que sejam relevante a tendinopatia dos flexores da mão.

$\mathrm{RC}: 77841$

Disponível em: https://www.nucleodoconhecimento.com.br/saude/tendoes-flexores 


\section{REFERENCIAL TEÓRICO}

O estudo da anatomia dos tendões flexores da mão se fundamenta como importante conhecimento para diagnóstico das patologias acometidas principalmente por trabalhadores, esportistas (amadores ou profissionais) e em geral todas as pessoas que fazem uso constante das mãos, a anatomia normal é a base necessária de todas as investigações médicas teóricas e práticas (BERNARD, 2002).

Mas qual a razão de se preocupar com a anatomia de um tendão? Ora se evitar erros de diagnóstico,

os tendões entram no compartimento central da mão e se abrem em leque para entrar nas respectivas bainhas sinoviais dos dedos. As bainhas dos músculos flexores e dos dedos permitem que os tendões deslizem livremente um sobre o outro durante os movimentos dos dedos (MOORE, 2014, p. 931).

Ainda segundo Moore os tendões de alguns músculos formam lâminas planas, ou aponeuroses, característica que pode ser confirmada através da palpação anatômica. Em Dangelo e Fattini (2007) pode-se dizer que tendões e aponeuroses fixam o musculo ao esqueleto. Essa afirmação vem constatar que o objetivo do tendão é movimentar a articulação, e também afirma que os tendões ou aponeuroses às vezes se prendem a outros elementos, pois ele pode estar inserido numa cartilagem, numa derme, ou em outras estruturas, com essa variedade de características, nos instiga a enorme importância em se estudar a anatomia dos tendões.

Enquanto Dangelo e Fattini (2007) afirma que o papel do tendão é movimentar as articulações, em Dalla Pria (2007) o autor deixa claro a função de estabilizar as articulações. Pensando no fato das articulações sofrerem estresse mecânico nos leva a pensar na consequência de tanto movimento, pois com tanta complexidade dessa estrutura anatômica é comum desenvolver patologias, entre elas temos a tenossinovite, que é uma das patologias que acometem um tendão, geralmente causada por um esforço repetitivo,

RC: 77841

Disponível em: https://www.nucleodoconhecimento.com.br/saude/tendoes-flexores 
A tenossinovite é muito similar à tendinite, pois envolve inflamação no tendão muscular. Entretanto, muitos tendões estão sujeitos ao aumento da quantidade de fricção por causa do estreitamento do espaço pelo qual ele deve se movimentar. Nessas áreas de elevada fricção, geralmente os tendões são envolvidos por bainhas sinoviais que reduzem a fricção durante o movimento. Quando o tendão que desliza por uma bainha sinovial é submetido ao esforço repetitivo, há probabilidade de ocorrer inflamação (PRENTICE, 2009, p.184).

Nessa linha de pensamento, conforme explicado acima uma tenossinovite é muito semelhante à tendinite. Segundo Eugene McNally (2015) já não se utiliza o termo "tendinite" e sim tendinopatia, que em tese é uma inflamação do tendão. Sizínio K. Hebert et al (2016) fala que o tratamento inicial para a tenossinovite estenosante deve ser conservador, utilizando exercícios de extensão e tala, havendo indicação de cirurgia quando:

Os pacientes são tipicamente considerados para a cirurgia quando uma tenossinovite persistir por mais de três meses, apesar do tratamento conservador razoável na forma de medicação, repouso, infiltrações com esteroides e terapia (DUTTON, 2010, p. 772).

Conforme citado acima no caso da tenossinovite, temos várias opções de tratamento, cabendo ao paciente e médico definir qual a opção.

\section{ANATOMIA DO TENDÃO FLEXOR}

Anatomia de um tendão flexor, mas o que é um tendão e qual a função de um tendão? Um tendão seria como um cordão esbranquiçado podemos então fazer uma analogia com o sistema de freio de uma bicicleta onde temos um cabo fino de aço (seria o tendão) que entra no flexível (bainha sinovial) e com uma correta lubrificação (liquido sinovial) desliza acionando a pinça de freio (seria uma estrutura anatômica produzindo movimento). Segundo Dangelo e Fattine (2007) Tendões e aponeuroses servem para fixar o músculo ao esqueleto, nosso trabalho demonstra que não é somente isso, e que devemos ir mais fundo em nosso estudo.

$\mathrm{RC}: 77841$

Disponível em: https://www.nucleodoconhecimento.com.br/saude/tendoes-flexores 
Neste contexto, fica claro que um tendão segundo Dalla Pria (2007) tem mais funções, ou seja, os tendões tem a função de absorção e produção de tensão no sistema muscular esquelético. Atribuindo assim mais uma função ao tendão.

Conforme explicado acima, o tendão acumula mais do que uma função, mesmo assim, não parece haver razão para nos aprofundarmos tanto num estudo de anatomia de um tendão flexor. Isso é um engano pois um bom profissional deve conhecer bem sobre o que esta lidando, e já percebemos que se procurarmos sempre um tendão inserido diretamente num osso poderemos errar em um diagnóstico, já que um tendão pode se inserir numa cartilagem ou numa derme.

Conforme verificado, em Skinner e McMahon (2014) casos congênitos levam ao tendão flexor do dedo mínimo ser dependente do tendão flexor do dedo anelar. Trata-se inegavelmente de uma afirmação onde o autor deixa claro que por uma ausência congênita, a flexão do dedo mínimo seria proporcionada pelo tendão flexor do dedo anelar, sendo um erro, atribuir à flexão do dedo mínimo somente ao tendão flexor do dedo mínimo. Assim, reveste-se de particular importância a anatomia dos tendões flexores. Sob essa ótima, ganha particular relevância aprofundarmos no estudo da referida anatomia.

Conforme mencionado pelo autor Dangelo e Fattine (2007) quando as extremidades são cilindroides ou então tem forma de fita, chamam-se tendões Assim podemos afirmar que os tendões têm a forma de uma corda. Neste contexto, fica claro que o tendão é formado por filamentos de tecido conjuntivo. E é importante lembrarmos que esse tecido conjuntivo é constituído por colágeno tipo I.

Ora, em tese, conforme explicado acima, temos uma estrutura conjuntiva de forma semelhante a um barbante, chegamos a esse tipo de conclusão após observamos um tendão. Caso contrário, sem uma correta observação da estrutura tendínea, poderia nos levar a cometermos enganos em um possível diagnóstico. Por exemplo, podemos confundir um tendão com um ligamento. Lamentavelmente poderíamos estar realizando alguma técnica de diagnóstico na estrutura errada.

$\mathrm{RC}: 77841$

Disponível em: https://www.nucleodoconhecimento.com.br/saude/tendoes-flexores 
Devido à disposição elástica em série desse tecido colagenoso, dão origem aos tendões, e os componentes elásticos paralelos apresentam função de sustentação da fibra muscular. Quanto maior a proporção de colágeno para as fibras elásticas, maior será o número de fibras que são orientadas na direção do estresse e, quanto maior a área transversal ou a largura do tendão, mais forte ele será. A propriedade viscoelástica do tecido é importante e corresponde ao limite de elasticidade e, se o alongamento continuar, pode resultar em lesão (SILVA, 2015, p. 29).

Na citação anterior, a autora deixa claro que o tendão tem uma propriedade elástica, a qual the confere uma boa resistência. Essa elasticidade se faz necessária, conferindo uma proteção para que o tendão não se rompa, com até certo grau de tensão. Esse é mais um motivo que nos leva a um desejo de conhecer mais sobre essa estrutura.

Ficam evidentes, diante desse quadro algumas propriedades estruturais do tendão, como elasticidade, resistência e sua forma que pode ser tipo uma corda ou uma fita. Espera-se, dessa forma, que estudando mais sobre a anatomia de um tendão flexor, possamos ser mais precisos num diagnóstico de uma tendinite, ou tenossinovite, É preciso ressaltar que o tendão ainda conta com mais duas estruturas, para evitar um possível dano ao músculo. O OTG Órgão Tendinoso de Golgi, que é um receptor proprioceptivo sensível à tensão muscular, fazendo com que o músculo diminua a contração, protegendo o mesmo contra danos como ruptura. A outra estrutura seria o fuso muscular (localizado no ventre muscular, mas com função de proteger o musculo e tendão), que ao contrario do OTG, protege o músculo de um estiramento maior que o suportado, realizando uma contração.

\section{PATOLOGIAS DO TENDÃO}

Tendinite, o que é? Neste capitulo abordaremos as principais patologias que um tendão flexor pode adquirir. A tendinite é uma inflação do tendão, mas segundo Mattioli; Faloppa (2013) O termo tendinite deve ser evitado, pois raramente há células inflamatórias no tendão, $O$ correto então seria utilizarmos 0 termo tendinose, que é uma degeneração do colágeno.

$\mathrm{RC}: 77841$

Disponível em: https://www.nucleodoconhecimento.com.br/saude/tendoes-flexores 
Pode-se dizer que segundo Mattioli; Faloppa (2013) tendinite é um termo errado. Neste contexto, fica claro que tendinose fica mais adequado. $\mathrm{O}$ mais preocupante, contudo, é constatar que essa condição não provém de inflamação.

Então conforme explicado acima, raramente se encontra células inflamatórias em um tendão. Então o que seria uma tendinose? Tendinose é uma alteração das fibras do colágeno ou morte das células tendíneas. Mas há um fato que se sobrepõe a nossas convicções, pois nem sempre numa tendinose há uma alteração do diâmetro do tendão.

Ensina-nos Mattioli; Faloppa (2013) Uma bainha composta de dupla camada de tecido sinovial pode circundar alguns tendões e, quando esses tecidos são envolvidos por inflamação, utiliza-se o termo tenossinovite. Assim também o autor deixa claro em Rumak et al. (2012) que a bainha que auxilia a fixação e deslizamento do tendão recebe o nome de bainha sinovial, composta de uma bicamada fibrosa e liquido sinovial que tem a função de lubrificar o tendão.

Pode-se dizer que a tendinose ou tenossinovite explicada acima, é agravada pelo excesso de utilização do tendão. Neste contexto, fica claro que a tendinose e a tenossinovite podem ser consideras uma LER (lesão por esforço repetitivo), conforme mencionado pelo autor, a tenossinovite seria a inflamação da bainha sinovial, diminuindo a quantidade de liquido sinovial, consequentemente aumentando o atrito tendão bainha. Não é exagero afirmar que Tendinopatia é uma descrição clínica para uma variedade de anomalias tendíneas agudas e crônicas (MATTIOLI; FALOPPA, 2013).

Conforme explicado acima, agora temos um termo geral para as patologias do tendão, que é tendinopatia. Formando assim mais um fator que nos leva a importância do estudo da anatomia do tendão flexor. Por exemplo, se for uma patologia na bainha sinovial (devemos saber identificar a bainha, não confundindo com uma cartilagem ou mesmo com um tecido conjuntivo) será tenossinovite. Se for

RC: 77841

Disponível em: https://www.nucleodoconhecimento.com.br/saude/tendoes-flexores 
uma degeneração nas fibras de colágeno então será uma tendinose, e se precisarmos generalizar podemos usar o termo tendinopatia.

As rupturas resultantes de traumas diretos sofridos pelos tendões ( $p$. ex., lacerações) são raras. A maioria das rupturas completas são resultados de tensão excessiva aplicada em movimento realizado em condições anormais. Em geral, as rupturas completas recentes dos tendões são diagnosticadas corretamente por meio do exame clinico. Se este não for feito logo, o diagnóstico poderá ser indeterminado em função de alterações inflamatórias. A USG pode demonstrar a descontinuidade de toda espessura do tendão (RUMAK et al, 2012, p. 918).

$\mathrm{Na}$ citação anterior o autor deixa claro que além dos problemas citados anteriormente (tendinose, tenossinovite) o tendão pode também sofrer ruptura de suas fibras. Podendo ser ocasionadas por vários fatores, como por exemplo, atividade física muito intensa. Patologias também podem provocar a ruptura de um tendão um exemplo seria o lúpus eritematoso, diabetes mellitus e gota.

Esses dados revelam muito mais do que simples patologias, ficando evidente, diante desse quadro, que o profissional que for tratar das patologias citadas dominem bem a anatomia de um tendão flexor. É preciso ressaltar que todos esses cuidados devem ser tomados também para os tendões extensores, pois essas estruturas tendíneas também tem suas particularidades, necessitando de outro estudo mais aprofundado sobre eles.

\section{DIAGNOSTICO}

O diagnostico será fechado clinicamente onde o fisioterapeuta pode se valer de exames de imagem, tais como: Ressonância Magnética, ultrassom. $E$ de testes ortopédicos como: Teste Sinal de Tinel, Tese de Phalen, Tese de Phalen Invertido, Teste de Finkelstein, Teste de Bunnel-Littler, Teste do tendão profundo, Teste do extensor e flexor longo do polegar, Teste do extensor comum dos dedos. Sem esquecer de uma boa anamnese, que trará o norte que o fisioterapeuta devera seguir.

$\mathrm{RC}: 77841$

Disponível em: https://www.nucleodoconhecimento.com.br/saude/tendoes-flexores 


\section{TRATAMENTOS FISIOTERAPÊUTICOS}

Neste capitulo abordaremos as técnicas fisioterapêuticas mais utilizadas para o tratamento da tendinopatia. Demonstramos algumas técnicas usuais, para que o estudante de fisioterapia possa ter um norte de como tratar a tendinopatia. Junto com o estudo da anatomia dos tendões flexores da mão e de suas principais patologias, se faz necessário, também ao profissional terapêutico dominar os diversos tratamentos.

Iniciaremos falando de técnicas de analgesia onde buscamos o controle da dor que o paciente apresenta. Se tratando de um processo inflamatório como uma tenossinovite ou de uma tendinose e ainda se o caso for ruptura do tendão na ocasião da dor poderemos utilizar, segundo Brumitt (2017) estimulação elétrica e crioterapia podem ser usados para ajudar a reduzir a dor e o edema e facilitar o progresso do atleta para as atividades e demandas de nível mais alto.

Nesta linha de raciocínio, Dutton (2009) recomenda em caso de inflamação, massagem com gelo, pela eficácia em controle da dor e edema. $\mathrm{O}$ autor deixa claro que o uso de gelo, é melhor aproveitado se for utilizado enrolado numa toalha, e aplicado diretamente na pele do paciente, do que utilizado em bolsas de gelo. Esse procedimento pode ser usado em casos de tendinopatia.

Outra técnica é a termoterapia, segundo Dutton (2009) a termoterapia deve ser utilizada na fase final de cicatrização, pois o calor pode danificar as fibras de colágeno do tendão. Com esse raciocínio devemos então considerar a termoterapia como opção mais indicada para ruptura do tendão, onde o aumento da vascularização pode ajudar na cicatrização do tendão rompido.

A eletroterapia promove analgesia porque melhora a circulação local Alves Neto (2009) o autor nos mostra outra técnica que podemos utilizar quando buscamos o controle da dor. A corrente elétrica galvânica atua diretamente na fibra muscular provocando contração muscular, estimulando a iontoforese nutrindo os tecidos e

RC: 77841

Disponível em: https://www.nucleodoconhecimento.com.br/saude/tendoes-flexores 
promovendo elasticidade musculotendínea. Já a corrente alternada atua nos nervos provocando vasodilatação e consequentemente controle da dor.

Chegou o momento de falarmos sobre a terapia manual. Segundo Alves Neto (2009) a técnica de relaxar e alongar o músculo devolve o comprimento de repouso ao músculo fadigado, restaurando sua potencia máxima. Podemos utilizar uma técnica de liberação miofascial, mobilização articular, manobra de estiramento com movimentos oscilatórios, utilizando movimentos passivos de flexão e extensão dos tendões flexores e extensores acometidos da patologia. Executando manobras passivas de deslizamento do tendão, lembrando sempre de observar se o paciente esta com agravo da dor, trabalhando a amplitude de movimento da articulação de forma suave, sutil e constante.

Outro recurso bem interessante é a laserterapia, que atua desinflamando os tecidos promovendo vasodilatação e um elevado fluxo de nutrientes.

Recomendo também o Pilates, que com sua enorme variedade de técnicas e exercícios de condicionamento e alongamento se torna uma alternativa muito interessante para o tratamento de tendinopatias.

Ruptura de tendão como agir? No caso de ruptura do tendão é aconselhável um acompanhamento com um cirurgião ortopédico onde o mesmo determinará a necessidade de uma tenorrafia ou não, no caso do paciente já ter feito a cirurgia, a fisioterapia deve adotar um procedimento conservador como os já citados aqui neste trabalho.

\section{CONSIDERAÇÕES FINAIS}

O desenrolar deste estudo teve o objetivo de fomentar a curiosidade acadêmica, para o estudo de uma estrutura anatômica, esquecida por muitos acadêmicos. Nos trouxe a uma profunda reflexão sobre as patologias acometidas pelo tendão flexor, bem como suas possíveis técnicas de tratamento.

RC: 77841

Disponível em: https://www.nucleodoconhecimento.com.br/saude/tendoes-flexores 
No contexto geral observamos que um tendão flexor tem peculiaridades especificas que 0 distinguem de outras estruturas anatômicas, que tem certa semelhança (ligamentos). Pudemos navegar no conhecimento de conceituados autores, verdadeiros mestres, que em suas obras nos orientam e estimulam a buscar cada vez mais conhecimento, em busca de um saber muitas vezes inalcançável.

Conseguimos com esta obra, não o absoluto conhecimento de um tendão flexor e suas patologias, mas auferimos o desejo inquietante do saber, do conhecer algo mais profundo, nos inquietamos com a descoberta, de que todo o aprendizado no curso de graduação foi só o começo do enorme iceberg que temos que vencer.

A cada particularidade descoberta, da anatomia do tendão flexor aprendemos um pouco mais sobre sua composição e forma. A cada patologia aqui decifrada nos questionávamos como vencê-la? E descobrimos que o primeiro passo para vencer uma patologia é conhecê-la, conhecer suas causas, e seus possíveis tratamentos. Navegamos intensamente nas terapias já conhecidas, e estávamos em devaneios imaginando um ou outro tratamento mais especifico.

Alavancando assim a necessidade de um trabalho mais profundo sobre o tema, após constatarmos a falta de material disponível sobre o assunto. Nunca tivemos a pretensão de esgotar o assunto com este trabalho, consciente que algo tão complexo deve ser objeto de estudo mais enraizado. Estudos estes que devem ser feitos em laboratórios com peças úmidas, ao qual durante este trabalho não tivemos acesso.

Com este discernimento permitimos ao leitor entender a anatomia de um tendão flexor, conhecer suas principais patologias, e seus principais tratamentos. Concluímos esta obra, exortando ao leitor a buscar cada vez mais, ampliando este singelo trabalho.

\section{REFERÊNCIAS}

RC: 77841

Disponível em: https://www.nucleodoconhecimento.com.br/saude/tendoes-flexores 
ALVES, Neto Onofre. Dor. Princípios e prática. 1aㅡ edição. Porto Alegre: Editora Artmed, 2009. ISBN-10 : 8536317019.

BANKOFF, Antônia Dalla Pria. Morfologia e cinesiologia: aplicada ao movimento humano. 1a edição. Rio de Janeiro: Editora Guanabara Koogan.2007. ISBN-10 : 8527712776.

BOTELHEIRO, José Carlos. (2018). Polegar "em mola" infantil. Pedipedia Retrieved February 20, 2019, disponível em: https://pedipedia.org/pro/artigoprofissional/polegar-em-mola-infantil acesso em 18/11/2020.

CLAUDE, Bernard. Introducción ó estudio da medicina experimental. $2^{a}$ edição de Clásicos do pensamento universal. Madri: Editora Univ. Santiago de Compostela, 2002. ISBN 978-84-97500-05-0.

DANGELO, José Geraldo \& Fattini Carlo Américo. Anatomia humana sistêmica e segmentar, 3ª edição. São Paulo: Editora Atheneu, 2007.

EUGENE, McNally. Ultrassonografia do Sistema Musculoesquelético. $2^{\underline{a}}$ edição. Rio de Janeiro Editora Guanabara Koogan. 2015. ISBN-13: 978-8535282887.

GIL, Antônio Carlos. Métodos E Técnicas De Pesquisa Social. 6ª edição. São Paulo: Editora Atlas. 2008. ISBN-13 : 978-8522451425.

JASON, Brumitt. Casos clínicos em fisioterapia esportiva. 1aedição Porto Alegre: Editora AMGH. 2017. ASIN : B074KMZSHF.

MARK, Dutton. Título Fisioterapia Ortopédica: Exame, Avaliação e Intervenção. $1^{a}$ edição. Porto Alegre: Editora Artmed. 2009. ISBN 9788536323718.

MARK, Dutton; Vezzani. Fisioterapia ortopédica: exame, avaliação e intervenção: 2ª edição. Porto Alegre: Editora Artmed. 2010. ISBN-10 8536322713.

$\mathrm{RC}: 77841$

Disponível em: https://www.nucleodoconhecimento.com.br/saude/tendoes-flexores 
MIGUEL, P. A. C. et al. Metodologia de pesquisa em Engenharia de Produção e gestão de operações. 2ª edição. Rio de Janeiro: Editora Elsevier . 2012. ISBN: 978-85-352-4850-0.

MOORE, Keith L. et all. Anatomia orientada para a clínica. tradução Claudia Lucia Caetano de Araujo. 7ª edição. Rio de Janeiro: Editora Koogan, 2014. ISBN 978-85277-2584-2.

Nelson, Mattioli Leite. Flávio Faloppa. Propedêutica ortopédica e traumatológica. 1a edição. Porto Alegre: Editora Artmed. 2013. ISBN-13: 978-8565852067.

PRENTICE, E. William. Fisioterapia na prática esportiva. 11ª edição. Porto Alegre: Editora AMGH, 2009.

RUMAK, Carol M. et al. Tratado de Ultrassonografia Diagnóstica. 4⿳亠丷a edição. Rio de Janeiro: Editora Elsevier. 2012. ISBN: 978-85-352-3940-9.

SIZÍNIO, K. Hebert. Ortopedia e Traumatologia: Princípios e Prática. $5^{\text {a }}$ edição: Editora Artmed. 2016. ISBN-13: 978-8582713761.

SILVA, Valeria Regina: Cinesiologia e biomecânica. 1aㅡ edição. Rio de Janeiro: Editora SESES. 2015. ISBN978-85-5548-135-2.

SKINNER, B. Harry. MCMAHON J. Patrick. Current Diagnóstico e tratamento: Ortopedia. 5ª edição. Porto Alegre: Editora AMGH. 2014. ASIN : B015QEGDAU.

Enviado: Fevereiro, 2021.

Aprovado: Março, 2021.

RC: 77841

Disponível em: https://www.nucleodoconhecimento.com.br/saude/tendoes-flexores 